DOI: $10.15503 /$ jecs20151.153.166

\title{
THE EFFECTIVENESS AND INFLUENCE OF VOCAL AND INSTRUMENTAL IMPROVISATION IN MUSIC THERAPY ON CHILDREN DIAGNOSED WITH AU- TISM. PILOT STUDY.
}

\author{
SARA KNAPIK-SZWEDA \\ Section of Creativity Pedagogy and Child's Expression, University of Silesia, \\ Michał Grażyński Street 53, 40-123 Katowice, Poland \\ E-mail address: knapik.sara@gmail.com
}

(a) $(\Theta \Theta$

\begin{abstract}
Autism is a developmental disorder which is difficult to recognize and diagnose. The present study examines the effectiveness of music therapy intervention based on improvisational techniques with the elements of Creative Music Therapy by Paul Nordoff and Clive Robbins and improvisational techniques by Tony Wigram (such as imitating, frameworking, dialogues, holding) on developmentl of children with Autism (two boys diagnosed with autism - case 1. and case 2), especially in verbal and nonverbal communication, disturbance behavior patterns, cognitive and social-emotional areas. The results indicate a positive outcome in two music therapy observing tools: Scale I Child - Therapist Relationship in Coactive Musical Experience Rating Form and Scale II Musical Communicativeness Rating Form. The tables indicate the intensity of interaction between the therapist and the subject during the music therapy process (including communication skills, cognitive skills and behavior patterns). The results of case 1 are indicated in Scale I and Scale II and show a significant effect of improvisational music therapy. The important findings from the analysis of behavior in the sessions were Stability and confidence in interpersonal musical relationship, Activity relationship developing, (scale 1.). The results of the case 2 . show small changes in musical behavior when it comes to Stability and confidence in interpersonal musical relationship, but in Activity relationship developing the indicators show a lot of changes between sessions. The results of the research indicate that music therapy intervention has a positive outcome and may be an effective method to increase functioning of children with autism.

Keywords: autism, music therapy, communication, behavior patterns, improvisation.
\end{abstract}

\section{INTRODUCTION}

Music therapy based on improvisation is an emotional, relational, motivational medium to communicate, express oneself and get the opportunity to understand others through music. Music making together-improvisation- and reciprocal interaction between therapist and subject is meaningful and significant in the therapeutic process. Within a musical process, a music therapist uses elements of music (rhythmic patterns, melody, beat, harmony, dynamics expression) which influence the subject's developmental areas, especially the clients diagnosed with Autism. 
Improvisation as a therapeutic tool contains a musical structure and a clearly systematic approach which engages the child in a musical activity in a safe environment. These music therapy techniques provide musical variability and flexibility to allow a therapist to get to the child in instrumental, vocal ways. Improvisation is the art of creating music spontaneously on the basis of nondirective activity. Tony Wigram claims that musical improvisation is a combination of sounds created within a certain structure which has its beginning and its end (Wigram, 2004). Clinical improvisation offers the musical partners the opportunity to comprehend one another directly through the music" (Procter, 2002). Children with autism need time to achieve therapeutic goals, such as: the development of verbal and nonverbal communication, reduction of stereotyped, repetitive behavior, improvement of social-emotional skills, cognitive skills, such as joint attention, concentration and memory. Improvisation helps them to improve, develop and change their lives.

Autism is a developmental disorder which is receiving much attention nowadays. According to the recent fifth edition, DSM-5, it can be characterized by two core symptoms: deficits in social communication and social interaction; repetitive patterns of behavior, interests, activities (Kern, Rivera, Chandler, Humpal, 2013). Autism and improvisation as music therapy techniques have a lot in common because they are still poorly known. The data has big potential because among numerous researches connected with improvisation and autism in Western Culture (Nordoff, Robbins 1965; Alvin 1978, 1991; Edgerton 1994; Wigram, 2000, 2006, 2009, Kim 2009; Gold 2009), they still provide some initial, although limited evidence about the efficacy of music interventions in the case of children with autism. The studies conducted in Poland still do not provide enough data and conclusions to present them. There is a need to conduct studies in Poland and indicate the influence of improvisation on communicative, social and cognitive development of a child, especially through two music therapy tools.

\section{PRoJeCT DeSIGN AND METHODOlOGY}

The study presents the influence of music therapy on boys ( 5 and 9 years old) diagnosed with Autism. The main goal of the study is: the influence of improvisation on a musical and nonmusical communication, social development and reduction of stereotyped, repetitive behavior. The project is based on qualitative assumptions in which all things, situations and events appear in the process, influence each other and have a specific effect. Besides, this qualitative approach discovers a significant meaning during the study, which is described by the researcher. The author also uses quantitative elements of study.

The project started in October 2011 and lasted until March 2012 with older boy and the second project started in October 2012 and lasted until April 2013 with a five-year-old boy. The sessions based on individual music therapy treatment and indirect approach took place once/twice a week. The music therapist used improvisational techniques based on the elements of Creative Music Therapy by Paul Nordoff and Clive Robbins (Nordoff, Robbins 1971) and improvisational 
techniques by Tony Wigram (therapist imitating each subject's musical material, movements and mood, dialogues-process where therapist and child/children communicate through their musical play, holding- therapist providing a rhythmic or tonal foundation for the subject's own improvisation, frameworking- where the therapist provides a functional and consistent musical structure within which the child's musical play fits) (Wigram 2004). Each session was recorded and described on the basis of two music therapy scales created by P. Nordoff and C. Robbins Scale I Child - Therapist Relationship in Coactive Musical Experience Rating Form and Scale II Musical Communicativeness Rating Form (Nordoff, Robbins 2007) which show changes in the distribution of musical and nonmusical behavior of a subject.

Scale I Child - Therapist Relationship in Coactive Musical Experience Rating Form has a structure of seven levels which show the experiences of relationship in musical activities and two sections: level of participation and qualities of resistiveness (for the purpose of this research, the part qualities of resistiveness was skipped) (model of the scale: appendix A). Level 1 presents various nonrelating behavior, such as: active rejection, non-accepting awareness, obliviousness. Level 2 indicates a tentative contact and prerelating acceptance. Level 3 and 4 present more consistent engagement of the child in musical interaction. Level 5 and 6 expose musical mutuality, self-confidence in musical expression. Level 7 is based on reciprocal, musical stability, the goals of individual therapy are realized at this level (Nordoff, Robbins, 2007). The scale is used to survey the overall complexity of child's responses during the sessions and expand the various levels of participation.

Scale II Musical Communicativeness Rating Form is realized through three modes of activity: instrumental, vocal and body movement (model of the scale: appendix B). Musical Communicativeness is also divided into 7 levels of communicativeness. Level 1 is based on non- musical communicative responses while level 7 presents enthusiasm for musical creativity and musical skills to build a musical bond. The last mode of activity was changed to stereotyped behavior (number of occurrence of non-communicative movements: rocking, swaying, jumping, twirling, finger movements, self-stimulation, aggressive behavior and others). In the conclusions, the author will present only two levels: level 2 evoked responses and level 6 which shows participation in musical interaction (participating communicative responsiveness). These scales (presented above) have not been used previously in Poland as experimental tools.

The subjects who participated in the study were: a boy (5 years old) with communication deficits (no eye-contact, no verbal communication, he could initiate a contact with the therapist but was unable to sustain it for a long time), repetitive behavior (stimulatory), cognitive and social disorders. A second client - a nine-year-old boy with communication disturbance, he used vocal stereotyped (echolalia), was unable to sustain a musical and nonmusical contact for a long time; he could not participate in a musical conversation based on turn-talking techniques; no eye-contact; disturbance in responses to sensory stimuli and behavior patterns. He participated in eight, recorded music therapy sessions because of health problems. The five-year-old boy participated in 14 sessions which are presented by the author. 


\section{INSTRUMENTS AND PROCEDURES}

The hypothesis of this research is: improvisation has a positive impact on subject's development, especially on the communication skills, the improvement of social skills and the reduction of stereotyped behaviors.

The independent variable is a variable that is the independent of the dependent variable or the variable that the researcher controls (Wheeler, 2006). In music therapy, the type of music, techniques, methods might be an independent variable. The independent variable in the study is music therapy based on vocal and instrumental improvisation, the dependent variables which measure the effects of the study are based on the functioning of children (communication, social skills and stereotyped behaviors). The indicators which are presented in the project are based on the number of occurrences of each subject's musical and nonmusical activities during each music therapy session. They are specified in Scale I Child Therapist Relationship in Coactive Musical Experience Rating Form (this behavior is, e.g. : stability and confidence in interpersonal musical relationship, mutuality and co-creativity in the expressive mobility of music, limited responsive activity, unresponsive non-acceptance) and Scale II Musical Communicativeness Rating Form (behavior such as: enthusiasm for musical creativity, sustaining of directed response, musical awareness, evoked responses which are presented in three areas: vocal, instrumental and stereotyped behaviors) (Nordoff, \& Robbins, 2007). Each session had the same structure: a good morning song which reflected the subject's mood and comfort; the vocal and instrumental improvisation which was the most meaningful part of the session and a goodbye song. This structure was stable and unchanging and it gave the subject a sense of security.

\section{DATA ANALYSIS}

The table no. 1 (a five-year-old boy) and the table no. 2 (a nine-year-old boy) indicate the intensity of interaction between the therapist and the subject during the music therapy process. The numbers from 0 to 4 show the number of occurrences of the subject's musical and nonmusical activities. The numbers on the top of a table present the dates of sessions. Each behavior is defined and described. Stability and confidence in interpersonal musical relationship was based on whether the client grasped a therapist's hand to use it to play the guitar (a five-year-old boy-case 1.) or sustain eye-contact when the therapist improvised in the Middle Eastern musical idiom on the piano (a nine-year-old boy-case 2.). Mutuality and co-creativity in the expressive mobility of music and Activity relationship was based on the subject's musical reaction to the specific sounds which reflected joy and good mood; each vocal improvisation created by the subject, the instruments which were used in the session (a special glockenspiel which was arranged in a pentatonic scale- case 1). By means of the glockenspiel, the boy modified and composed different sounds which he created with the therapist. It showed his self-confidence in music creating. He also ceased to behave stereotypically during the play on the glockenspiel as he had to focus on playing. 
The most important experience was a reciprocal music making together based on musical turn- talking (Wigram, 2007) (case 1.). Case 2 indicated musical awareness, enthusiasm for musical creativity, especially in vocal improvisation when he created many songs based on his vocal stereotype with the therapist accompanying and reflecting the subject's material song based on his vocal stereotypeSally Bowls's Song or Electronic Equipment Song. The essential moments in music therapy sessions were when the boy was waiting for a musical response from the therapist. Sometimes, he directed a therapist's hand to play on the piano or he stopped stimulation and focused on the therapist's musical material (case 2). He also discovered many sounds of the piano, drums and cymbals. Limited responsive activity was based on stereotyped behavior (case 1 and 2) or coming to the window and not perceiving the therapist and her play (case 1.). During the sessions, the boy (case 2) was sustaining a musical response through playing the piano in the same intervals or drum (very loudly and intensively) which disrupted any musical and non-musical communication. Unresponsive - the client wanted to finish the sessions and leave the room (case 1) or he was talking about the end of the session (case 2). Below, the accurate changes of behavior are presented (case 1 and case 2). For example, working relationship on the first session did not appear at all, on the last session happened twice. Limited responsive activity on the first session appeared three times, and on the last- not at all. (Tabel 1 Scale I Child - Therapist Relationship in Coactive Musical Experience Rating Form). Case 2- working relationship on the first session did not appear at all, on the last session happened three times. Limited responsive activity on the first session and the last session appeared three times. (Tabel 2 Scale I Child - Therapist Relationship in Coactive Musical Experience Rating Form). 


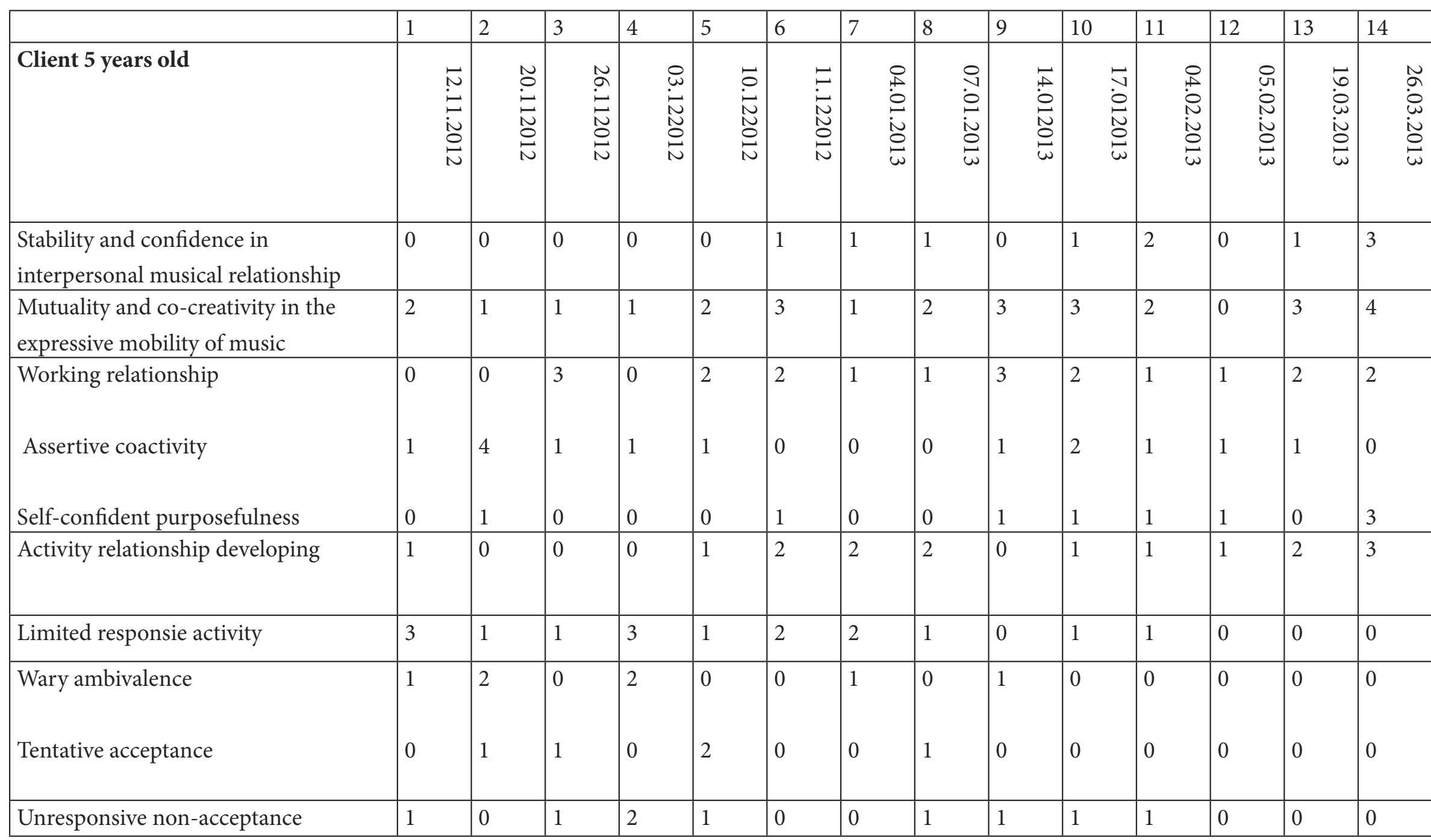

Tab. 1. Scale I Child - Therapist Relationship in Coactive Musical Experience Rating Form (a five-year-old boy)

Source: Own calculations and modifications based on: P. Nordoff, C. Robbins (2007. p. 374). 


\begin{tabular}{|c|c|c|c|c|c|c|c|c|}
\hline & 1 & 2 & 3 & 4 & 5 & 6 & 7 & 8 \\
\hline Case 2. A nine-year-old boy. & $\begin{array}{l}\overrightarrow{0} \\
\dot{0} \\
\dot{0} \\
0 \\
=\end{array}$ & 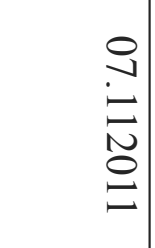 & 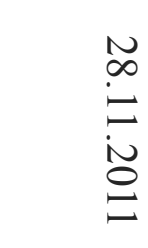 & $\begin{array}{l}\text { Nu } \\
0 \\
\stackrel{0}{N} \\
\stackrel{0}{N}\end{array}$ & 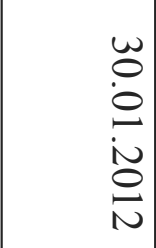 & 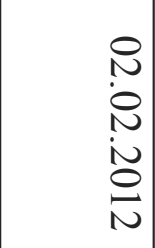 & 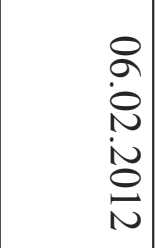 & $\begin{array}{l}0 \\
\dot{y} \\
\dot{0} \\
\dot{N} \\
\stackrel{0}{N}\end{array}$ \\
\hline Stability and confidence in interpersonal musical relationship & 0 & 0 & 0 & 0 & 0 & 0 & 2 & 1 \\
\hline Mutuality and co-creativity in the expressive mobility of music & 1 & 1 & 1 & 1 & 0 & 2 & 2 & 0 \\
\hline Working relationship & 0 & 0 & 1 & 2 & 3 & 3 & 8 & 3 \\
\hline Assertive coactivity & 4 & 4 & 2 & 3 & 0 & 1 & 3 & 1 \\
\hline Self-confident purposefulness & 0 & 2 & 1 & 3 & 8 & 6 & 3 & 3 \\
\hline Activity relationship developing & 1 & 1 & 0 & 0 & 1 & 2 & 4 & 1 \\
\hline Limited responsie activity & 3 & 3 & 2 & 3 & 2 & 0 & 1 & 3 \\
\hline Wary ambivalence & 1 & 1 & 0 & 0 & 0 & 1 & 0 & 0 \\
\hline Tentative acceptance & 0 & 1 & 3 & 4 & 2 & 1 & 0 & 3 \\
\hline Unresponsive non-acceptance & 2 & 0 & 1 & 2 & 3 & 2 & 0 & 4 \\
\hline
\end{tabular}

Tab. 2. Scale I Child - Therapist Relationship in Coactive Musical Experience Rating Form (a nine-year-old boy) Source: Own calculations and modifications based on: P. Nordoff, C. Robbins (2007, p. 374). 


\section{RESULTS OF THE RESEARCH}

The results of the project study are appropriately indicated by the Scale II Musical Communicativeness Rating Form, which has also been modified by the researcher. Scale II is a very similar to scale I (it has a specific musical and nonmusical behavior which are scored in the same way as scale I). It presents musical communicativeness based on three areas: vocal, instrumental and stereotyped behaviors. The chart below shows one selected behavior - Participation in musical interaction and Evoked responses. On the first part, left side of the figures are presented results of the beginning of the research, the second part, on the right side of the figures are indicated results of the end of the research in both cases.

Case 1. We can notice a difference in a number of occurrences of three activities (especially in instrumental activity and a small differences in vocal and movement areas in Participation in musical interaction). On the first part of the chart, the behavior which was based on communicative skills occurred once, but on the last session the musical behavior occurred more often - four times. Evoked responses- we can also observe more noticeable differences between areas. (Figure 1, Chart based on Scale II Musical Communicativeness Rating Form and Figure 2, Evoked responses. Chart based on Scale II Musical Communicativeness Rating Form).

Fig. 1. Participation in musical interaction (a five-year-old boy)

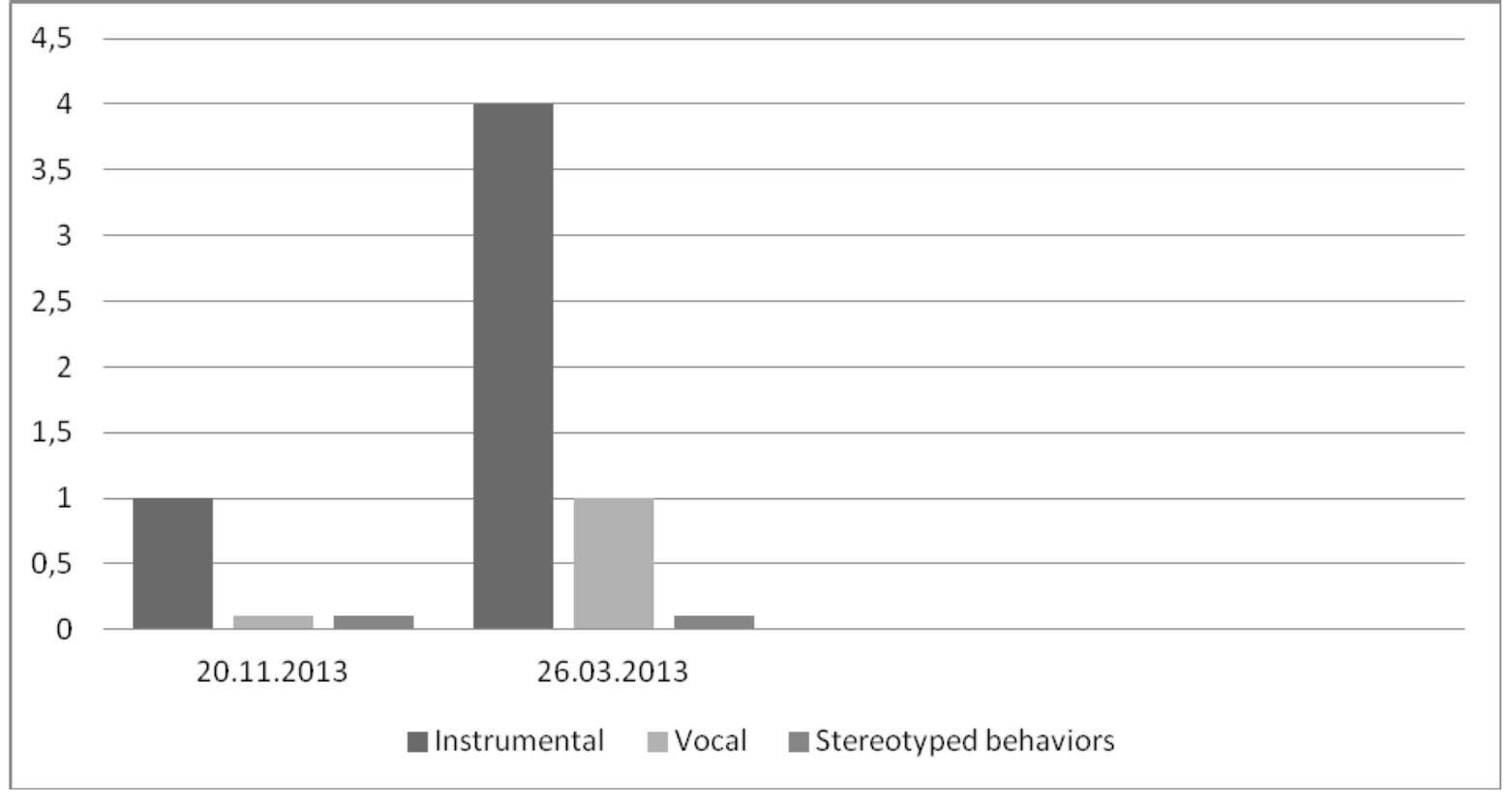

Source: Chart based on Scale II Musical Communicativeness Rating Form (Nordoff, Robbins, 2007, p. 417). 
Fig. 2. Evoked responses (a five-year-old boy)

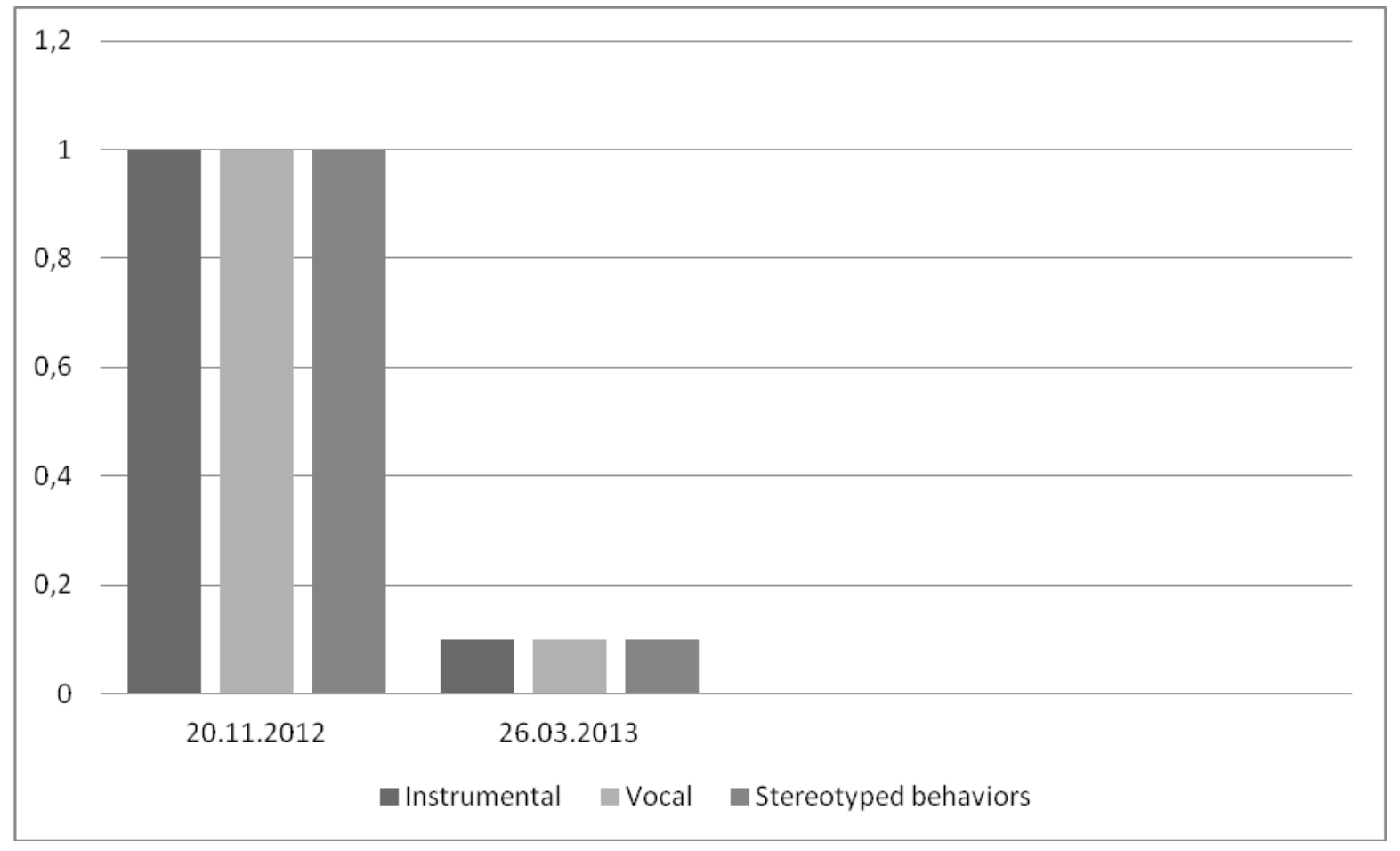

Source: Chart based on Scale II Musical Communicativeness Rating Form (Nordoff, Robbins, 2007, p. 417).

Case 2. In this case, we also notice a difference in a number of occurrences of three activities. Participation in musical interaction- on the first session and the last session participation in musical interaction based on instrumental activities occurred twice (with no changes). Vocal interaction was observed on the last session as one activity. Stereotyped behavior occurred four times on the first session, but on the last session, stereotyped behavior was reduced to one. Evoked responses appeared in total six times (instrumental, vocal, stereotyped behavior) on the first session. The Second part of the chart indicates that evoked responses occurred three times on the last session, especially in stereotyped behavior, as a musical rejection. (Figure 3, Chart based on Scale II Musical Communicativeness Rating Form and Figure 4 Evoked responses .Chart based on Scale II Musical Communicativeness Rating Form). 
Fig. 3. Participation in musical interaction (a nine-year-old)

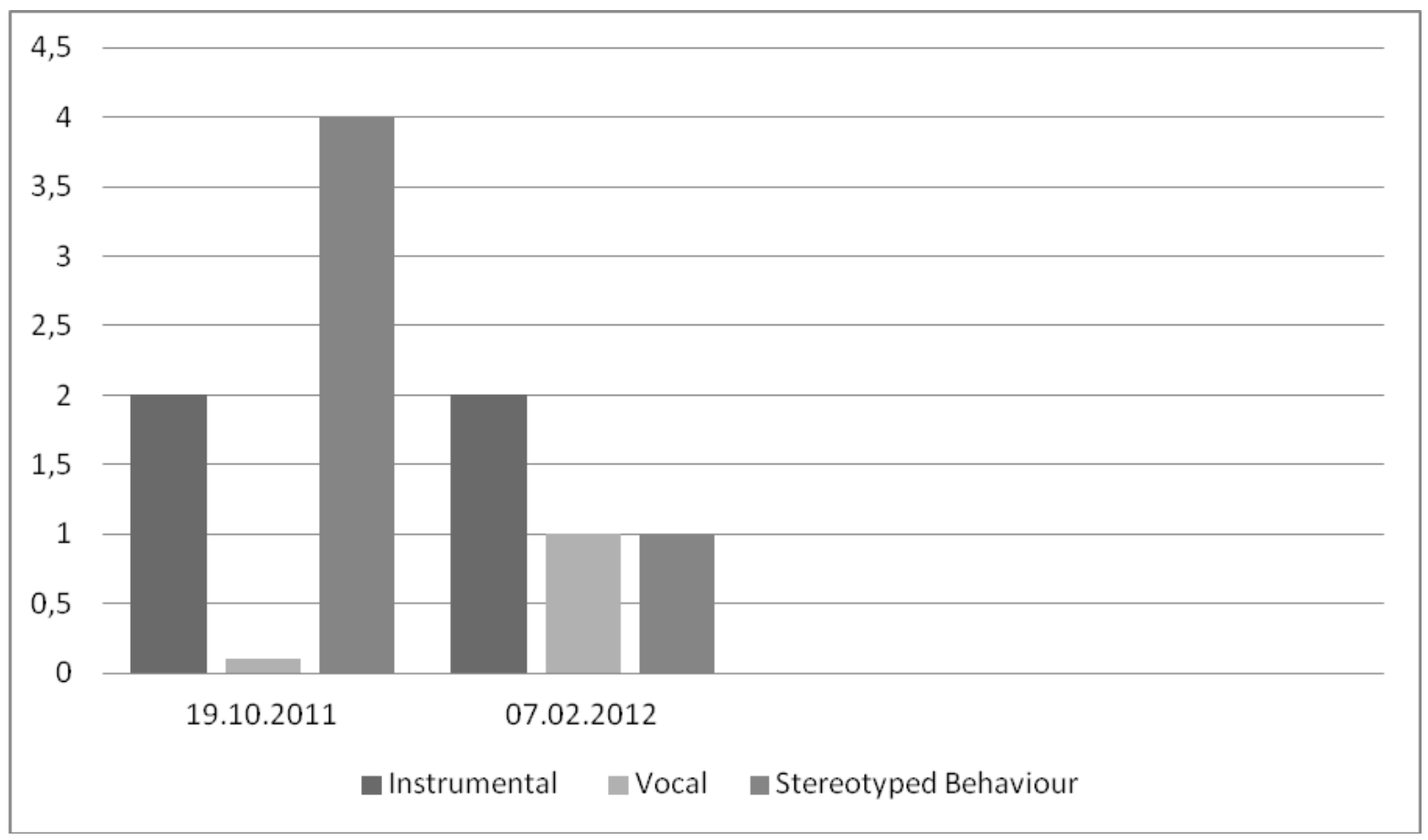

Source: Chart based on Scale II Musical Communicativeness Rating Form (Nordoff, Robbins, 2007, p. 417).

Fig. 4 Evoked responses (a nine-year-old boy)

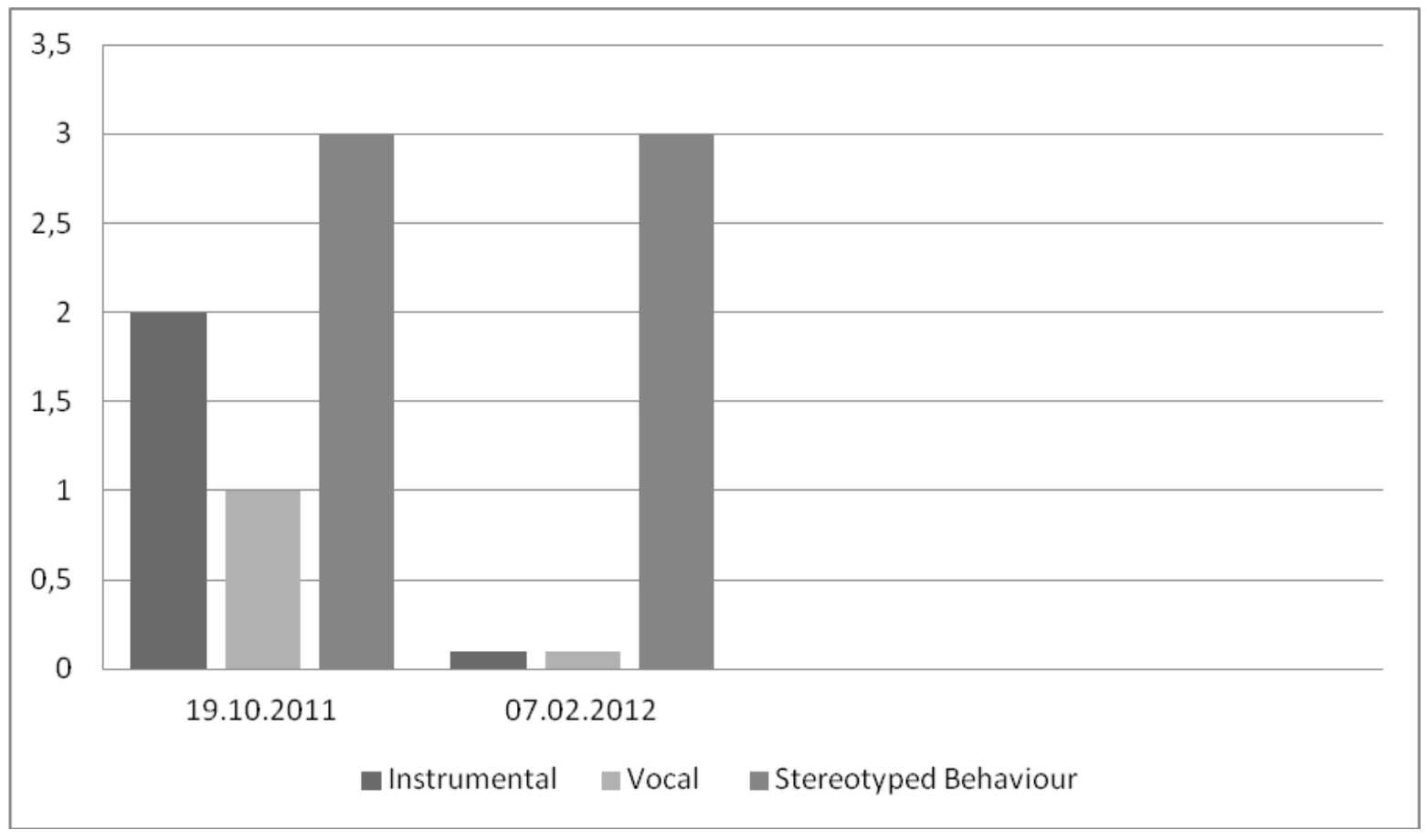

Source: Chart based on Scale II Musical Communicativeness Rating Form (Nordoff, Robbins, 2007, p. 417). 


\section{DISCUSSION}

The results of the case 1 are indicated in Scale I Child - Therapist Relationship in Coactive Musical Experience Rating Form and Scale II Musical Communicativeness Rating Form and show a significant effect of improvisational music therapy. The important findings from the analysis of behavior in the sessions were Stability and confidence in interpersonal musical relationship, Activity relationship developing, (scale 1.), Participation in musical interaction (scale II). There were positive outcomes in Limited responses (scale I) and Evoked responses (scale II) whose number of occurrences decreased in the last session.

The results of the case 2. show small changes in musical behavior when it comes to Stability and confidence in interpersonal musical relationship, but in Activity relationship developing the indicators show a lot of changes between sessions (especially differences between the first session and the seventh session). There were positive outcomes in Evoked responses (scale II) and Limited responses (scale I). On the first session six evoked responses occurred, on the last sessions there were only three. This is a result of reduced limited responses in this case. Participation in musical interaction (scale II) - there were no significant changes in instrumental interaction. The changes occurred in stereotyped behavior reduced from four indicators to one.

The improvisation was proved to be a meaningful music therapy technique as it allowed us to achieve therapeutic purposes. Based on scales, observations and recordings, the outcomes emphasize that nonverbal communication (making and sustaining contact between the subject and the therapist; the gradual extension of eye-contact) was improved in both cases. Through musical dialogues, each client could learn the turn-talking rules and listening skills through controlling themselves. Throughout the process, there was a reduction of repetitive behavior and the frequency of the behavior was limited (during the videotape, the five-year-old client was gradually ceasing inappropriate behaviors when he was playing the glockenspiel or participated in instrumental improvisation). Cognitive deficits were improved particularly in terms of joint attention, concentration, memorizing and reflecting (imitation). In both cases, there were changes in social skills, especially in reciprocal interaction with the therapist in a music therapy process.

\section{CONCLUSION}

The results of the research indicate that music therapy intervention in a child treatment program has a positive outcome and may be an effective method to increase a holistic functioning of children with autism. The author emphasizes that despite the systematic music therapy with two children, the results have been positive, and can enrich the understanding of the phenomenon that is the impact of music therapy on the development of autistic children. However, the study is qualitative with the elements of quantitative research, therefore, the author does not generalize the results of studies on a larger population. The author emphasizes the value of the study project and indicates that music therapy, its properties can be a positive and meaningful form of therapy in therapeutic intervention of children with autism. In addition, the author emphasizes the need for broader studies 
of children with autism and music therapy based on improvisation or other music therapy techniques in order to more fully demonstrate its positive effects.

\section{SUMMARY}

The author of the study sought to demonstrate visible and positive results and the great potential of improvisation as a music therapy technique which can influence every child, regardless of disorder or disability. Its features allow creation of a musical and nonmusical relationship between the child / participant in the therapy and the therapist, which is the essence of music therapy. The author wants to create the next research project to improve the usage of therapeutic tools and research methods and to expand knowledge about music therapy and autism. She hopes that the above-mentioned musical experience of the two boys and their musical and non-musical skills will continue to develop.

\section{REFERENCES}

Aigen, K. (1998). Paths of Development In Nordoff-Robbins Music Therapy. Gilsum: NH Barcelona Publishers. Alvin, J., \& Warwick, A. (1991). Music therapy for the autistic child. New York: Oxford University Press. Boso, M., Emanuele, E., Minazzi, V., Abbamonte, M., \& Politi, P. (2007). Effect of Long-Term Interactive Music Therapy on Behavior Profile and Musical Skills in Young Adults with Severe Autism. The journal of alternative and complementary medicine, 13 (7), 709-712.

Brandalise, A. (2004). Music Therapy: The Use of Music for Healing. Music Centered Music Therapy Studies. Voices A World Forum for Music Therapy, 4 (1), Retrieved from https://voices.no/ index.php/voices/article/view/139/115.

Bruscia, K. E. (1998). Defining Music Therapy. Gilsum: NH Barcelon Publishers.

Bruscia, K. (Ed.). (2006). Case study in music therapy. Third Edition. Gilsum: NH Barcelona Publishers.

Bruscia, K. (2001). A Qualitative Approach To Analyzing Client Improvisations. Music Therapy Perspectives, 19 (1),7-22.

Bruscia, K. (1988). A Survey of Treatment Procedures in improvisational Music Therapy. Psychology Music, 16, 1-24.

Davis, W. B., Geffler, K. E., \& Thaut, M. H. (1998). An Introduction to music therapy. Theory and Practise. Second Edition. USA: The McGraw-Hill Companies.

Edgerton, C. (1994). The effect of improvisational music therapy on the communicative behaviors of autistic children. Journal of Music Therapy, 21(1), 31-62.

Frith, U. (2008). Autyzm. Wyjaśnienie tajemnicy [Autism. Explaining the Enigma]. GWP: Gdańsk.

Gold, C., \& Wigram, T. (2006). Music therapy for autistic spectrum disorder. Cochrane Database of Systematic Reviews, Issue 1, Retrieved form http:/ / www.ebp-slp.com/pdfs/music-therapy/MusicTherapyandAutism.pdf

Kern, P., Rivera, N. R., Chandler, A., \& Humpal, M. (2013). Music Therapy Services for Individuals with Autism Spectrum Disorder: A Survey of Clinical Practices and Trainig Needs. Journal of Music Therapy, 50(4), 274-303.

Kim, J., Wigram, T., \& Gold, Ch. (2009). Emotional, motivational and interpersonal responsiveness of children with autism in improvisational music therapy. Autism, 13 (4), 389-409.

Lee, C. (2000). A Method of Analyzing Improvisations in Music Therapy. Journal of Music Therapy, 37 (2), 147-167.

McFerran-Skewes, K. (2003). Contemplating the Nature of Adolescent Group Improvisations, Voices A World Forum for Music Therapy, 3 (3), Retrieved from https://voices.no/index.php/voices/ article/view/133/109

Nordoff, P., \& Robbins, C. (2007). Creative Music Therapy. A Guide to Fostering Clinical Musicianship. Second Edition. Gilsum: Barcelona Publishers.

Nordoff, P., Robbins C. (2007). Terapia muzyka w pracy z dziećmi niepetnosprawnymi [Music Therapy for Handicapped Children]. Impuls: Kraków. 
Pavlicevic, M. (2002). Dynamic Interplay in Clinical Improvisation. Voices A World Forum for Music Therapy, 2 (2), Retrivied from https://voices.no/index.php/voices/article/view/88/70

Pavlicevic, M. (2000). Improvisation in Music Therapy. Human Communication in sound. Journal Music Therapy, 37 (4), 269-285.

Procter, S. (2002). The therapeutic, musical relationship: a Two - Sided Affair. A consideration of the Terapeutic's Siginficance of the Musical Input In Co-Improvisation, Voices A World Forum for Music Therapy, 2 (3). Retrieved from https://voices.no/index.php/voices/article/view/102/79

Ruud, E. (1998). Music Therapy, Improviasation, Communication and Culture. Gilsum: Barcelona Publishers.

Wheeler, B. L., Shultis, C. L., \& Polen, D. W. (2005). Clinical Training Guide for the Student Music Therapist. Gilsum: NH Barcelona Publishers.

Wheeler, B. L. (Ed.). (2005). Music therapy research. Second Edition. Gilsum: Barcelona Publishers

Wigram, T. (2004). Methods and Techniques for Music Therapy Clinicians, Educators, and Students. London: Jessica Kingsley Publishers.

Appendix A Scale I Child - Therapist Relationship in Coactive Musical Experience Rating Form

IIt HVAIIIAIIIIN

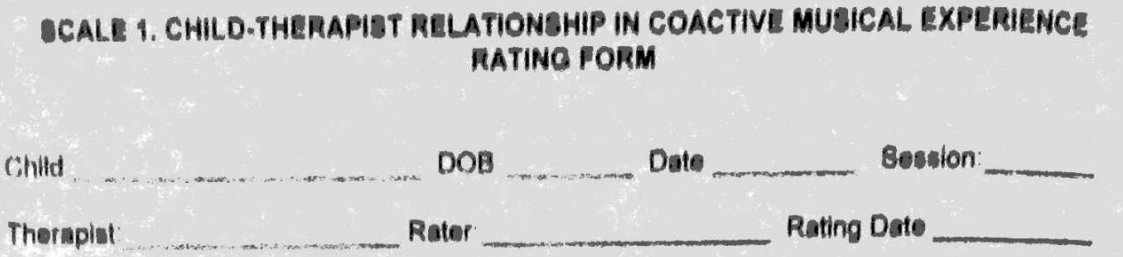

$P$ LEVELS OF PARTICIPATION QUALITIES OF RESISTIVENES8

(7) _..... J Stability and confidenee in

Through identifieation with sense interpersonal musical relation. of accomplishment and wall-being ship. $\quad$ resists own regreselve tendeneles.

(6) ..... Mutuality and eo-oreativity in the expresalve mobility of music.

a) Crisis-toward resolution.

b) No resistivenese.

(5) V

Assertive coactivity.

Working relationahip. Self-confident purposefulness.

Perseverative compulsivenese. Assertive inflexibility

Contest.

(4) $\backslash \ldots, \vee \downarrow \vee$ Activity relationship developing

6)

Perversity and/or manipulativenoss

1

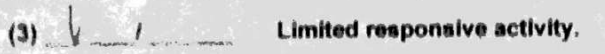

Evasive defensiveness

(2)

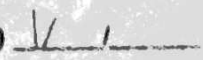

(1)
Unresponsive non-acceptance.

Wary amblvalence.

Tentative aceeptance.
Apparent obliviousness.

Active rejection.

Panic/rage reaction when pressed. 
Appendix B Scale II Musical Communicativeness Rating Form

\section{SCALE II MUSICAL COMMUNICATIVENESS \\ RATING FORM}

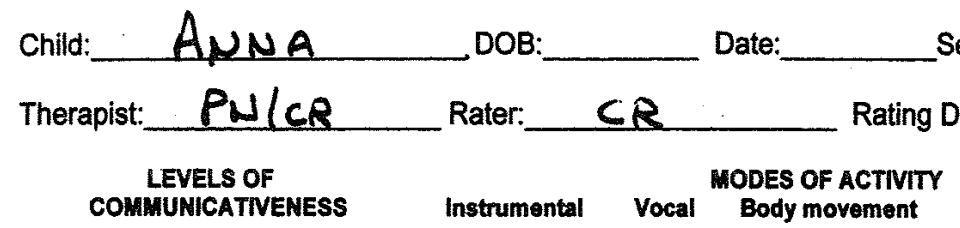

(7) Musical intelligence and skills freely functioning and competently, personably communicable. RATING TOTALS Enthusiasm for musical creativity.

(6) Participating communicative responsiveness firmly established. Growing musical self-confidence. Independence in using thythmic, melodic, or expressive components.

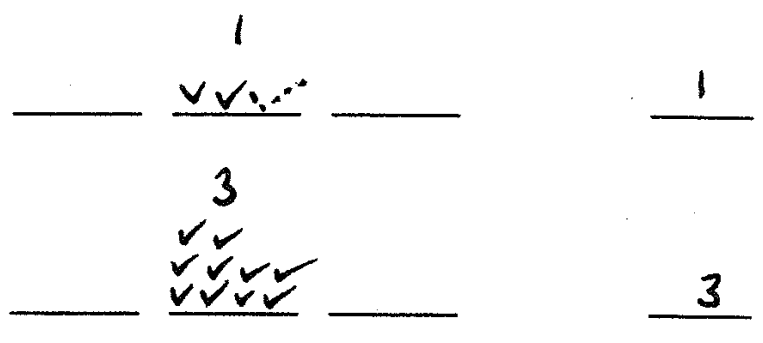

(5) Sustaining of directod response impulses setting up musica! communication. Musical motivation appearing. Involvement increasing.

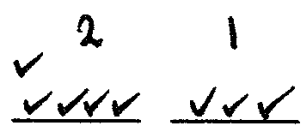
Session:

(4) Musical awareness awakening. intermittent musical perception and intentionality manifesting.

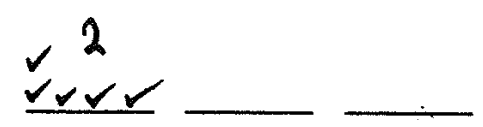

(3) Evoked responses (ii): more sustained and musically related

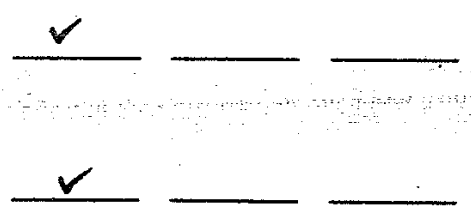

(2) Evoked responses (i): fragmentary, fleoting.

(1) No musically communicative responses

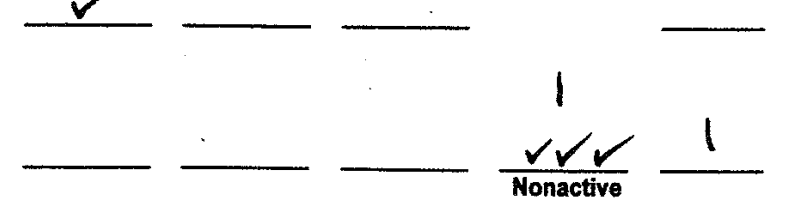

Figure 5 